\title{
The prevalence, risk factors predicting injury and the severity of injuries sustained during competition in professional mixed martial arts in Africa
}

\author{
S Venter, ${ }^{1}$ MSc; D C Janse Van Rensburg, ${ }^{1}$ MD; L Fletcher, ${ }^{3}$ \\ $\mathrm{PhD}$; C C Grant, ${ }^{1} \mathrm{PhD}$ \\ ${ }^{1}$ Section Sports Medicine, Faculty of Health Science, University of Pretoria, \\ Pretoria, South Africa \\ 2Institute for Sports Research, University of Pretoria, Pretoria, South Africa \\ ${ }^{3}$ Department of Statistics, Faculty of Natural \& Agricultural Sciences, \\ University of Pretoria, Pretoria, South Africa
}

\section{Corresponding author: S Venter (drventer@yahoo.com)}

Background: Professional mixed martial arts (MMA) has gained international popularity. No African-based studies have reported the prevalence or severity of injuries, risk factors associated with injuries or return-to-play (RTP) time. Objectives: To determine the prevalence of injuries and associated risk factors, as well as severity of injuries sustained by professional male MMA athletes competing at the Extreme Fighting Championships Africa (EFC Africa) from 2010 to 2014.

Methods: Permission to do the study and the medical records of all professional events $(2010$ - 2014) were obtained from EFC Africa. Data were obtained from 173 male competitors aged 18 to 44 years, who had participated in 300 professional MMA fights. Results from this prospective cohort study were compared to a similar study done in the United States of America (USA). An injury was defined as any damage to an athlete's body that needed the attention of the ringside physician. Statistical analyses included descriptive statistics and a stepwise logistic regression. Odds of an injury were predicted with six independent variables: fight outcome, age, weight division, number of fights, injuries in the preceding fight and years of fighter experience.

Results: Head, face and neck injuries were most common (22\%), followed by traumatic brain injuries (knockouts) (6\%). Losing a fight was a significant predictor of injury when using the stepwise logistic regression model $(p=0.040)$. The odds ratio indicated that a preceding fight injury almost doubled the risk of injury in the following fight (OR 1.91; $\mathrm{p}=0.163$ ). Traumatic brain injuries (TBIs) in this study of African-based competitions $(6 \%)$ were substantially higher than reported in the American study (1.8\%).

Conclusion: Head, neck and face injuries are common in African fighters. The high rate of TBIs in African competition compared to the USA study is concerning. This could reflect superior refereeing in the USA group, as fights may be ended sooner by stoppage. Further investigation of injury trends and preventative measures should be studied to reduce the incidence of injuries during African competitions.

Keywords: mixed martial arts, concussion; return-to-play

S Afr J Sports Med 2017;29:1-5. DOI: 10.17159/2078-516X/2017/v29i0a1471

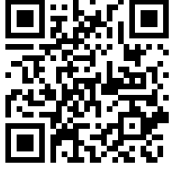

Mixed martial arts (MMA) is a full-contact, unarmed combat sport that allows striking and grappling techniques. ${ }^{[1]}$ This includes karate, Jeet-Kune-Do, kung-fu, Muay-Thai, boxing, kickboxing, judo, taekwando, ninjitsu, wrestling, jiu-jitsu and Brazilian Jiu Jitsu (BJJ). MMA has evolved into a sport represented by numerous bodies around the world. ${ }^{[2]}$ The Ultimate Fighting Championship (UFC) based in America is regarded as the world dominant MMA platform. In 1996, Arizona Senator John McCain described MMA as "human cockfighting", and sent letters to the governors of all fifty USA states asking them to ban the event. Thirty-six states banned the "no-holds-barred" fighting. In response to all the criticism, the UFC redesigned its rules to remove the unpalatable elements of the fights, while retaining the core elements of striking and grappling. This lead to the creation and implementation of the New Jersey State Athletic Control Board's Unified Rules ${ }^{[3]}$ in November 2000, which are obeyed in most professional regulated MMA competitions around the world. These rules, aimed at increasing the safety of competitors, helped promote the mainstream acceptance of the sport. MMA in Africa is regulated by the International Mixed Martial Arts Federation (IMMAF) ${ }^{[4]}$, and the Unified Rules apply to EFC Africa.

MMA competitions have male and female divisions, each with their own weight divisions. Competitors wear compulsory safety gear (4 ounce or 113.4g gloves, mouth guard and groin protector). Fights take place in a three $\mathrm{m}^{2}$ hexagon/ring fenced in area. This area has a $2.5 \mathrm{~cm}$ padded floor and two entrances. All exposed metal is covered. Competitors have to pass a basic medical examination and screening tests for Human ImmunoDeficiency Virus (HIV) and hepatitis. Normally fights consist of three 5-minute rounds with a one-minute rest period between rounds. However, championship bouts consist of five 5-minute rounds. A qualified referee oversees the MMA fight and can use his/her discretion to stop the fight.

During the fight, all rules need to be adhered to and if disobeyed, may result in disqualification. The rules ban headbutting, eye-gouging, fish-hooking, groin attacks, fingers into orifices/lacerations, small joint manipulation, 90 degree elbows, blows to the back of the head, blows to the kidney with the heel, throat strikes and grabbing of the trachea/clavicle, kicking/kneeing the head of a grounded opponent, stomping a grounded opponent, and spiking an opponent to the canvas on his head/neck. A fighter can win a match in different ways: submission (verbal/tap out); knockout (KO); technical knockout (TKO); or decision via scorecards. The fight can also be declared a draw, disqualification, forfeit, technical draw/decision or no contest.

Ten competitions are hosted in South Africa every year by the EFC. More than 300 athletes have competed at EFC Africa since its inception in 2009. Despite the popularity of MMA in Africa there is no information about the prevalence, severity and risk 
factors associated with injuries during competition. Therefore the aim of this study was to determine the prevalence and severity of injuries, as well as risk factors associated with sustaining injuries in professional MMA competitions in Africa.

\section{Methods}

\section{Study design}

A prospective cohort study was designed using medical records as documented by an accredited ringside physician. The Research Ethics Committee of the University of Pretoria approved the study after permission from the custodian of the data, EFC Africa, was confirmed.

\section{Participants and demographics}

All injuries sustained by athletes competing at EFC Africa events from 5 August 2010 to 14 June 2014 were included in the study ( $\mathrm{n}=300$ fights or 600 fight exposures). Competitors consisted of 173 male athletes between the ages of 18 and 44 years. Only male athletes were included in this study as professional female MMA in Africa was only introduced in 2015.

\section{Medical data collection}

Medical records were obtained from the event medical support team with the permission of the custodian of the data; EFC Africa. An accredited ringside physician recorded these records immediately after the fight, reporting all injuries sustained according to anatomic location, type of injury and injury severity. The anonymity of the injured fighter was maintained and the average return-to-play (RTP) time after injury was considered an indicator of the severity of the injury.

Data obtained included the date of the fight, total number of fights, total injuries (damage to an athlete's body that needed the attention of the ringside physician), outcome of the fight, competitor's age at the date of the fight, weight divisions, years of experience, injuries sustained in the previous fights, injuries sustained in the current fight by anatomic location and severity, time between fights and time off until RTP. Data were compared to a study conducted by $\mathrm{Ngai}^{[5]}$, reviewing injury trends in 635 professional USA MMA fights from 20022007.

\section{Statistical analysis}

The statistical analysis included descriptive statistics and a stepwise logistic regression model using IBM SPSS Statistics 22. Odds of an injury were predicted with the following independent variables: fight outcome, age, weight division, number of fights, injuries in the preceding fight and years of fighter experience. These results were also compared to a similar study by Ngai as previously mentioned. This study also used the term "fight exposures" as used in the Ngai study, indicating that two athletes are exposed to injury per fight. Similarly, the injury odds ratios were calculated using logistic regression including match outcome, weight, age and fight experience, during a pair-matched case-control study design $(n=464)$. Cases were also defined as fighters who sustained an injury/received medical attention during the matches, and controls were defined as fighters who were uninjured.

\section{Results}

\section{General}

Table 1 summarises fight exposures, the total number of injuries and total number of traumatic brain injuries (TBIs). Of the 300 fights (600 exposures), 295 fights ended with a 'win' result for one fighter and a 'loss' result for the other fighter. Two fights were cancelled before taking place, two fights ended in draws and one fight was deemed a 'no contest'. Among the 600 professional MMA fight exposures included in the study, 222 total injuries were reported. The injury rate is thus 37 per 100 fight exposures.

\section{Percentage of injuries according to anatomic location}

Table 2 reflects the total prevalence of injuries in the present study by anatomic location and average RTP following specific injuries. Injuries to the head, face and neck were the most common $(22 \%)$, followed by TBIs due to knockouts $(6 \%)$, upper limb injuries (4\%), lower limb injuries (3\%) and injuries to the torso/back/ribs (2\%). One death due to intra-cerebral haemorrhage resulted from an MMA fight during the study period.

Fifteen fractures were reported (Table 3). The most common fractures sustained were rib fractures (5), followed by metacarpal (4) and metatarsal fractures (2). Only two

Table 1. Fight exposures, total injuries and total traumatic brain injuries (TBIs)

\begin{tabular}{cccc}
\hline Year & $\begin{array}{c}\text { Number of } \\
\text { fight } \\
\text { exposures\# }\end{array}$ & $\begin{array}{c}\text { Injuries } \\
\mathbf{n}(\mathbf{\%})\end{array}$ & $\begin{array}{c}\text { TBIs } \\
\mathbf{n}(\%)\end{array}$ \\
\hline Overall & 600 & $222(37)$ & $50(8)$ \\
$\mathbf{2 0 1 0}^{*}$ & 70 & $21(27)$ & $7(10)$ \\
$\mathbf{2 0 1 1}$ & 120 & $47(34)$ & $13(11)$ \\
$\mathbf{2 0 1 2}$ & 154 & $57(34)$ & $11(7)$ \\
$\mathbf{2 0 1 3}$ & 180 & $60(31)$ & $13(7)$ \\
$\mathbf{2 0 1 4}^{* *}$ & 76 & $37(49)$ & $6(8)$ \\
\hline
\end{tabular}

n, number of participants; TBIs, Traumatic Brain Injuries.

\#Two athletes are exposed to injury per fight. ${ }^{*}$ As from 5 August $2010 .{ }^{* *}$ As at 14 June 2014.

Table 2. Prevalence of injuries and return-to-play (RTP)

\begin{tabular}{lcc}
\hline \multicolumn{1}{c}{ Body region } & $\begin{array}{c}\text { Injuries } \\
\mathbf{n}(\mathbf{\%})\end{array}$ & $\begin{array}{c}\text { Average RTP } \\
\mathbf{( 9 5 \%} \mathbf{C I})\end{array}$ \\
\hline Upper limb & $25(4)$ & 3.7 weeks $(2.8 ; 4.4)$ \\
Lower limb & $21(3)$ & 7.7 weeks $(0.2 ; 15.2)$ \\
Head/face/neck & $130(22)$ & 2.2 weeks $(2.0 ; 2.3)$ \\
TBIs (KO) & $34(6)$ & $* 4$ weeks \\
Torso/back/rib/groin & $12(2)$ & 3.5 weeks $(2.2 ; 4.8)$ \\
Total number of \\
injuries
\end{tabular}


dislocations occurred during the study period and both involved the shoulder joint. Injuries to the face included 16 episodes of epistaxis, and five auricular hematomas.

\section{Return- to- play (RTP) times}

Lower limb injuries were responsible for the longest time off play. The average RTP after injury was 7.7 weeks. Lower limb injuries included anterior cruciate ligament (ACL) and posterior cruciate ligament (PCL) ruptures, for which the average RTP is one year. Two of these injuries were recorded during the study period, thus contributing to the increased RTP average.

RTP averages 3.7 weeks following upper limb injury, with metacarpal fractures contributing mostly to the prolonged recovery time. A four-week period is the average time needed to recover from TBIs/hypoxia. This follows the 30 day knockout rule.

Injury to the torso/back/rib/groin requires 3.5 weeks until RTP (rib fractures and soft tissue injuries). Following a head/face/neck injury, RTP averages 2.2 weeks.

The most regular time lapse between all fight exposures, whether athletes were injured or uninjured, was three months ( $84 \%$ ), but may vary between 22 days and four years. The three month time lapse most frequently represents the time fighters take to rest after preparing for a fight and subsequently competing. Certain athletes compete again after a shorter time lapse, depending on their conditioning and motivation for competing (financial gain, title contention, etc.).

\section{Logistic regression: Injury prediction}

Logistic regression models were used to compare injured athletes to non-injured athletes. (Table 4). The odds ratio of an injury were modelled using four independent variables: the outcome of the fight, the age of the athlete, the weight division and the number of fights. The results of this logistic regression were compared to a study conducted by $\mathrm{Ngai}^{[5]}$ in the USA, using the same predictors. Three models were constructed: Model 1 included the above-mentioned four predictors; in Model 2, two more predictors were added, i.e. injuries sustained in the preceding fight and the total years of experience of each fighter. For Model 3 a stepwise logistic regression was performed to identify possible predictors of injury (with a stepwise procedure, only significant predictors are included in the model).

In SA Model 1 no single predictor was found to be significant for predicting an injury, although there is moderate to strong quality evidence that losing a fight is a predictor ( $\mathrm{p}=0.052)$, controlling for age, weight and number of previous fights. The additional two predictors in SA Model 2 (years of experience and injury in the previous fight) were also not significant. However, losing a fight was a significant predictor of injury when controlling for the other five explanatory variables. Using stepwise logistic regression (SA Model 3), losing a fight was again a significant predictor of injury in that fight $(\mathrm{p}=0.041)$. The odds ratio $(\mathrm{OR})$ indicated that losing the previous fight doubles the risk of injury (OR 2.02). A preceding fight injury also more than doubles the risk
Table 3. Injury prevalence by anatomic location (excluding brain injuries)

\begin{tabular}{|c|c|c|c|c|c|}
\hline $\begin{array}{c}\text { Body } \\
\text { region }\end{array}$ & $\begin{array}{c}\text { Soft } \\
\text { tissue } \\
\text { injury }\end{array}$ & Fracture & Dislocation & $\begin{array}{c}\text { Ligament } \\
\text { rupture }\end{array}$ & \\
\hline Hand & 8 & 4 & & & \\
\hline Elbow & 5 & 1 & & 1 & \\
\hline Shoulder & 3 & 1 & 2 & & \\
\hline Foot & 8 & 2 & & & \\
\hline Ankle & 4 & & & & \\
\hline Knee & 5 & & & 2 & \\
\hline $\begin{array}{l}\text { Head/ } \\
\text { face/neck }\end{array}$ & 128 & 2 & & & \\
\hline $\begin{array}{l}\text { Torso/ } \\
\text { back/rib }\end{array}$ & 5 & 5 & & & \\
\hline Groin & 2 & & & & \\
\hline Total & 168 & 15 & 2 & 3 & 188 \\
\hline
\end{tabular}

Table 4. Logistic regression results

\begin{tabular}{lccc}
\hline & \multicolumn{3}{c}{ Comparison of injured vs. non-injured athletes } \\
\hline & \multicolumn{3}{c}{ Odds ratio (OR) (p-value) } \\
\cline { 2 - 4 } SA Model 1 & SA Model 2 & SA Model 3 \\
\hline Losing fighter & 2.04 & 2.16 & 2.02 \\
& $(0.052)^{* *}$ & $(0.040)^{*}$ & $(0.041)^{*}$ \\
Age & 1.05 & 1.03 & - \\
& $(0.313)$ & $(0.515)$ &
\end{tabular}

\section{WeightII}

$\begin{array}{lcc}\text { Number of } & 1.09 & 1.05 \\ \text { Fights } & (0.218) & (0.545)\end{array}$

$\begin{array}{lcc}\text { Years of } & - & 1.01 \\ \text { Experience } & & (0.788)\end{array}$

$\begin{array}{lccc}\text { Injured in } & - & 1.92 & 2.19 \\ \text { previous fight } & & (0.163) & (0.060)^{* *}\end{array}$

\section{SA, South Africa}

*Significant at the $5 \%$ level of significance. ${ }^{* *}$ Significant at the $10 \%$ level of significance. II Weight was entered in the model as a categorical variable with six different weight divisions.

of injury in the following fight (OR 2.19; $\mathrm{p}=0.060$ ).

\section{Discussion}

Overall injury prevalence appears to be as high as 37\% in the present study compared to only $24 \%$ in the USA study by Ngai. ${ }^{[5]}$ The total percentage of TBIs in the African-based competitions $(6 \%)$ is also substantially higher than in the USA-based competitions (2\%). Losing a fight was a significant predictor of injury when employing a stepwise logistic regression model $(\mathrm{p}=0.041)$, doubling the risk of sustaining an injury in the following fight (OR 2.02). Fighters who sustained an injury in the preceding fight also more than doubled the risk of sustaining an injury in the following fight (OR 2.185, $\mathrm{p}=0.06$ ) (Table 4).

The total percentage of injuries averaged 37\% between 2010 and 2014 (Table 1). A substantial increase in the amount of TBIs was recorded in 2011. Possible causes could include 
competitor-dependent variables such as inexperience, poor weight-cutting techniques and injuries sustained during training; unrealistic RTP periods; poor refereeing or application of rules and safety measures; and poor prefight medical screening. There was also a dramatic increase in the percentage of injuries sustained during 2014 (Table 1 ). This may be an indication of superior post-fight medical assessment of fighters by experienced sports physicians.

Professional MMA fighters have a three times higher injury rate than amateur MMA fighters. ${ }^{[6]}$ It is the author's opinion that this could be ascribed to a higher level of competition, or it could also be due to the lack of protective gear and the legality of knee and elbow strikes to standing/grounded opponents in the professional fights. Further studies are advised in this regard.

\section{MMA and concussion}

The Ngai study ${ }^{[5]}$ reports that $36 \%$ of all injuries in MMA occur to the head/neck/face region which is higher than the $22 \%$ rate reported in the SA study. Approximately $7 \%$ of fights end in a $\mathrm{KO}$ in the USA study as compared to $6 \%$ in the SA study. Scoggin et al. ${ }^{[6]}$ found that $20 \%$ of injuries sustained during MMA bouts were concussions resulting in brief (<15seconds) loss of consciousness and/or retrograde amnesia.

Head-impact (also implying concussion) in MMA training and competition is common. Head injuries occur in other contact sports, and in a multitude of non-contact sports. ${ }^{[7]}$ Boxing carries a high rate of head injuries with the highest rate of sport-related mortality due to TBIs. ${ }^{[8]}$ A recent article, however, claims that cyclists have the highest rate of sportsrelated TBIs. ${ }^{[9]}$ Other contact sports in which TBIs frequently occur include ice-hockey, Muay-Thai, kick-boxing and rugby. Non-contact sports in which athletes sustain regular concussions include soccer, basketball, skiing, lacrosse, baseball, basketball, snowboarding, skateboarding and motocross. Many head injuries in athletes are the result of improper playing techniques and this can be reduced in African athletes through the teaching of proper skills and enforcing safety promoting rules. ${ }^{[10]}$

\section{Safety gear and TBIs}

The use of protective headgear has remained a controversial topic of discussion. The main viewpoints regarding the use of headgear are, firstly, the ability to decrease the impact of strikes to the head, and thereby limiting the incidence of TBIs. The International Boxing Association (AIBA) banned amateur boxers from wearing headgear in a bid to reduce the incidence of concussion. This decision supports the second point of view, following an internal study by Wang ${ }^{[11]}$, showing that a lack of headgear actually reduces the risk of concussion. Researchers agree that while headgear can help to avert other serious head and facial injuries, there was no scientific evidence proving that it contributes to the prevention of concussion, and, paradoxically, it may even encourage fighters to take greater risks. Repeated, sub-concussive hits to the head damage the blood-brain-barrier and are also linked to chronic traumatic encephalopathy later in life. ${ }^{[12]}$ Headgear can obscure peripheral vision, making it harder to see when a blow is aimed at the side of the head.

The use and size of gloves regarding MMA and boxingrelated head injuries are also controversial. Strikes to the head were less common in the bare-knuckle era because of the risk of hand injuries. Gloves reduce the incidence of lacerations to the face, but research has stated that gloves do not reduce TBIs and may even increase the incidence. ${ }^{[13]}$ This is explained by considering head acceleration-deceleration as the mechanism of injury leading to a concussion. Large gloves force fighters to deliver an increased number of more forceful strikes to the head (higher striking rate and acceleration) in order to achieve a KO.

\section{RTP}

A much disputed area of combat sport is the return of fighters to competition after injury. ${ }^{[14]}$ The most debated issue is the time lapse during this convalescent period and how it differs for specific injuries (head injuries, fractures, dislocations, etc.). Concussions are often missed, while their detection and management are imperative, as mismanagement of this syndrome can lead to persistent/chronic post-concussion syndrome or diffuse cerebral swelling. ${ }^{[15]}$ In keeping with international standards, EFC Africa requires fighters to undergo a pre-fight uncontrasted Computerised tomography (CT) brain scan. No fighters are allowed to return to competition after suffering a KO loss in a fight within 30 days (the 30-day knockout rule). The average RTP after injury varies from 2.2 weeks to one year, depending on the type, anatomic location, and severity of injury. The 30-day knockout rule is a mandatory medical suspension that applies to all athletes who suffered TBIs during competition. Unfortunately, it is difficult to assess athletes for TBIs sustained during training and the onus of RTP following such injuries is largely placed on the athletes themselves and their coaches.

Choke submissions as a method of victory occurred in $10 \%$ of MMA fights included in this study. These manoeuvres are reported separately, as the mechanism involved in causing loss of consciousness while being choked differs from that of a $\mathrm{KO}$. Choke submissions induce temporary brain hypoxia, whereas KOs are related to acceleration-deceleration TBIs. Thus choke submissions cannot be regarded as concussions. Joint submissions contributed to a win result in 3\% of cases, and injuries sustained due to these manoeuvres are subsequently reported as upper or lower limb injuries.

\section{Injuries}

Although TBIs are the most feared injuries in MMA, other less serious injuries occur regularly. These include auricular haematomas, orofacial, head, limb, torso and groin injuries.

The submission-grappling component has increased the incidence of strains and dislocations to the shoulder, elbow, wrist, knee and ankle joints respectively. The striking component is largely responsible for injuries to the face, head, ribs, long bones and soft tissue of the extremities.

\section{Conclusion}

The pool of professional MMA athletes in Africa is small (161 signed athletes) compared to the thousands of athletes 
competing in the USA. One professional MMA event is held in SA every month, while several events take place in the USA on a weekly basis. This study is the first comprehensive analysis of injuries sustained in professional MMA competition in Africa to date.

Further studies are advised to record injury trends, including the risk factors associated with injuries and the severity of injuries in professional MMA. The concussion rate during training and the subsequent RTP should be studied to minimise incidents of exposing concussed athletes to competition too early. Pre-fight Magnetic Resonance Imaging (MRI) studies, although expensive, could aid in the detection of training-related concussions.

This study provides the most comprehensive analysis of ringside physician-collected data on professional male MMA fighters in Africa. No study has included the possible predictors of injury or the RTP time, making this study a valuable aid to fighter safety for fighters, physicians, promoters and referees. Only one study has reviewed the epidemiology of injuries in MMA, and this included amateur and professional athletes of both genders. ${ }^{[6]}$

Although much has been done to improve fighter safety by the introduction of the Unified Rules of Conduct ${ }^{[3]}$, MMA still remains a contact sport with limited control over the incidence of injuries.

This study recorded the prevalence of injuries, the risk factors associated with sustaining an injury and the severity of injuries during competition in Africa.

\section{The value of this study}

This study has highlighted the following:

- The overall prevalence of injuries during MMA competition in Africa from 2010-2014 was as high as $37 \%$;

- The incidence of life-and/or limb-threatening injuries appears higher when compared to the USA study;

- Risk factors for sustaining an injury in competitive professional African athletes include an injury in the previous fight and losing the current fight;

- $\quad$ TBIs in the African based competition study (6\%) was substantially higher than the USA study by $\mathrm{Ngai}^{\left[{ }^{[5]}\right.}$ $(1.8 \%)$.

Thus this study contributes to enhancing overall fighter safety by creating awareness among sanctioning bodies, trainers, referees, sports physicians and fighters:

- Losing a fight vs. injury correlation: A focus on mental toughness and additional care should be given to losing fighters;

- RTP should not be considered before full recovery;

- $\quad$ Fights may be ended sooner due to referee stoppage.

Further studies are needed to aid in maximising the safety of MMA fighters by educating the sanctioning bodies, trainers, referees, sports physicians and fighters.

\section{References}

1. Little JR, Wong CF. Ultimate Martial Arts Encyclopaedia.1st ed. McGraw-Hill 2000:3-32.

2. Garcia SR, Malcolm D. Decivilizing, civilizing or informalizing? The international development of mixed martial arts. Int Rev Soc Sport 2010;45(1): 39-58. http://doi.org/10.1177/1012690209352392

3. New Jersey State Athletic Control Board. Mixed Martial Arts Unified Rules of Conduct. http://www.state.nj.us/lps/sacb/docs/martial.html (accessed 25 March 2015).

4. International Mixed Martial Arts Federation. http://www.immaf.org

5. Ngai KM, Levy F, Hsu EB. Injury trends in sanctioned mixed martial arts competition: a 5-year review from 2002 to 2007 . Br J Sports Med 2008;42(8):686-689. [https://doi.org/10.1136/bjsm.2007.044891] [PMID: 18308883]

6. Scoggin JF $3^{\text {rd }}$, Brusovanik G, Pi M, et al. Assessment on injuries sustained in mixed martial arts competition. Am J Orthop (Belle Mead NJ) 2010;39(5):247-251.

https://www.ncbi.nlm.nih.gov/m/pubmed/20567743/ [PMID: 20567743]

7. Cantu RC. Head injuries in sport. $\mathrm{Br} \mathrm{J}$ Sports Med 1996;30(4):289-296. http://doi.org/10.1136/bjsm.30.4.289

8. Baird LC, Newman CB, Volk H, et al. Mortality resulting from head injury in professional boxing: case report. Neurosurgery 2010;67(2):E519-520.

[https://doi.org/10.1227/neu.0b013e3181e5e2cd]

[PMID: 20644386]

9. Hinck M, Sims I. Jamaica Hospital Warns: Bicyclists Suffer More Brain Injuries Than Football Players. http://medisyshealth.org/publicAffairs/pressRelease/articlebyl d.php?id=73 (accessed 23 January 2015).

10. Jordan BD.The clinical spectrum of sport-related traumatic brain injury. Nat Rev Neurol 2013;9(4):222-30 [https://doi.org/10.1038/nrneurol.2013.33] [PMID:23478462]

11. Wang SS. Boxing group bans headgear to reduce concussions. The Wall Street Journal. 2013 http://www.wsj.com.news/articles/SB1000142412788732339330 4578360250659207918 (accessed 10 May 2016).

12. Gavett BE, Stern RA, McKee AC. Chronic traumatic encephalopathy: a potential late effect of sport-related concussive and sub-concussive head trauma. Clin Sports Med 2011;30(1):179-188. https://doi.org/10.1016/j.csm.2010.09.007

13. British Medical Association. Boxing debate. May 2002. http://bma.org.uk/ap.nsf/Content/Boxing+debate+ (accessed 10 May 2016).

14. Sedney CL, Orphanos J, Bailes JE. When to consider retiring an athlete after sports-related concussion. Clin Sports Med 2011;30(1):189-200. Available at [https://doi.org/10.1016/j.csm.2010.08.005] [PMID:21074092]

15. Harmon KG, Drezner JA, Gammons $M$, et al. American Medical Society for Sports Medicine position statement: concussion in sport. Br J Sports Med 2013; 47(1):15-26. http://doi.org/10.1136/bjsports-2012-09194 